\title{
Finite Element Analysis of EA 113 Gasoline Engine Connecting Rod
}

\author{
Jing Zhang, Zhiyuan Qiu", Yan Zhang \\ College of Vehicles and Energy, Yanshan University, Qinhuangdao, China \\ Email address: \\ zhangjing@ysu.edu.cn (Jing Zhang), qzy930930@163.com (Zhiyuan Qiu) \\ ${ }^{*}$ Corresponding author
}

\section{To cite this article:}

Jing Zhang, Zhiyuan Qiu, Yan Zhang. Finite Element Analysis of EA 113 Gasoline Engine Connecting Rod. International Journal of Mechanical Engineering and Applications. Vol. 5, No. 4, 2017, pp. 208-213. doi: 10.11648/j.ijmea.20170504.14

Received: June 16, 2017; Accepted: June 30, 2017; Published: July 19, 2017

\begin{abstract}
For the Santana EA 113 gasoline engine connecting rod, the motion law of connecting rod and stresses in movement were analyzed using the theory knowledge of kinematics and dynamics. Based on the finite element method, the three-dimensional model of four-cylinder four-stroke gasoline engine connecting rod was established and then the stiffness and stress distribution and strain condition of connecting rod under different working conditions were analyzed. In modal analysis and transient dynamic analysis, the frequencies of rod in resonance and the stress, displacement and velocity of connecting rod at each moment were obtained, which provide the basis for the optimal design of connecting rod.
\end{abstract}

Keywords: Gasoline Engine, Connecting Rod, Finite Element Analysis, Modal, Transient Dynamic

\section{Introduction}

The connecting rod plays an important role in the work of gasoline engine. It's subjected to the reciprocating inertia of the piston and its rotational force with the crankshaft in actual work. In addition, it will be subjected to many complex external loads in the process of movement, and these loads change periodically [1-2]. The reliability of connecting rod has become an important aspect in the research and improvement of the performance of automotive engine. With the continuous development of the automobile design technology, especially the rapid development of computer technology, using the finite element method to analyze the stress and the optimization of the connecting rod is gradually taken seriously [3-6]. The lightweight design of the engine has become a big problem that can't be ignored in the whole process of whole vehicle development. To achieve the lightweight of the engine, the main components of engine must be optimized to reduce the volume and weight [7-8].

In recent years, many scholars at home and abroad have made lots of analysis and researches on the engine connecting rod by using the finite element method. At present, the researches mainly focus on the both ends and body of the connecting rod [1-2] [9-10]. Assuming that the stresses at the small end of connecting rod and the shaft section of body are already determined, they kept them certain values during the optimization process and apply them to the structural optimization design module as boundary conditions [3].

This study takes Santana EA 113 gasoline engine connecting rod as the research object, analyzes the effects of various forces in the connecting rod through the analysis of kinematics and dynamics. And then the three-dimensional model of connecting rod was established and transient dynamics analysis, modal analysis and analysis of stress and strain were adopt to the connecting rod by using the finite element method under considering the influences of external forces and complex movement. Firstly this research performed static analysis on the connecting rod to obtain stress distributions and strain conditions, and then applied modal analysis to rod to analyze the dynamic characteristics. Through the above research, the existing problems and the weak links of the structure in connecting rod were found, which provide the theoretical basis for the optimization design and structural improvement of the connecting rod [6] [9] [11-12].

\section{Main Structural Parameters}

This study takes Volkswagen Santana EA 113 engine with displacement of $1.781 \mathrm{~L}$ as the research object, makes finite 
element analysis to the connecting rod. The engine is a four-cylinder four-stroke gasoline engine with mechanical supercharging, the speed $n=5200 \mathrm{r} / \mathrm{min}$, the main parameters of engine are shown in Table 1.

Table 1. Main structural parameters of engine.

\begin{tabular}{ll}
\hline Parameter & Value \\
\hline Piston diameter $D(\mathrm{~mm})$ & 81 \\
Displacement $V_{s t}(\mathrm{~L})$ & 1.781 \\
Piston stroke $S(\mathrm{~mm})$ & 86.4 \\
Compression ratio $i$ & 9.5 \\
Speed $n(\mathrm{r} / \mathrm{min})$ & 5200 \\
Crank radius $r(\mathrm{~mm})$ & 43.2 \\
\hline
\end{tabular}

One of the main requirements for the design of the connecting rod is to ensure maximum stiffness and strength at the lowest weight as much as possible. Therefore, it's required to design the shape and size of connecting rod reasonably and use high strength material. This research selects the high quality medium carbon steel of featured carbon content (45\#). The engine connecting rod selects the flat incision which is better than oblique incision in the terms of force and manufacturing. The main parameters of the connecting rod are shown in Table 2.

Table 2. Main parameters of the connecting rod.

\begin{tabular}{|c|c|c|}
\hline Position & Parameter & Size $(\mathbf{m m})$ \\
\hline \multirow{4}{*}{ Small end } & Pore diameter $\mathrm{d}_{1}$ & 26.00 \\
\hline & External diameter $\mathrm{D}_{1}$ & 32.50 \\
\hline & Breadth $\mathrm{B}_{1}$ & 33.80 \\
\hline & Bush thickness $\delta_{1}$ & 2.00 \\
\hline \multirow{3}{*}{ Body } & Length 1 & 151.2 \\
\hline & Section width B & 22.68 \\
\hline & Section height $\mathrm{H}$ & 36.29 \\
\hline \multirow{4}{*}{ Big end } & Breadth $\mathrm{B}_{2}$ & 32.40 \\
\hline & Bush thickness $\delta_{2}$ & 1.50 \\
\hline & Boss at big end $\mathrm{H}_{1}$ & 24.31 \\
\hline & Boss at big end $\mathrm{H}_{2}$ & 23.23 \\
\hline \multirow{3}{*}{ Bolt } & Diameter $d_{M}$ & 8.00 \\
\hline & Interporal lacuna $\mathrm{C}$ & 69.00 \\
\hline & Pore outside thickness d' & 3.00 \\
\hline
\end{tabular}

According to the main parameters, the connecting rod was modeled and meshed, which was shown in Figure 1.

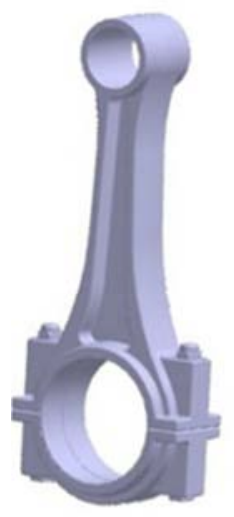

(a) Model

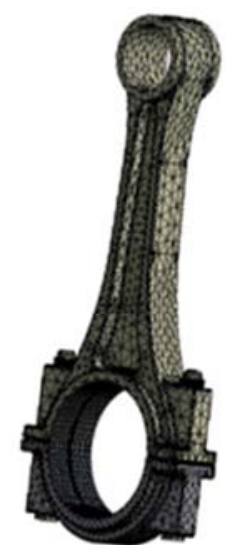

(b) Mesh
Figure 1. Model and mesh of connecting rod.

\section{Motion and Force Analysis}

\subsection{Kinematic Analysis}

The forces acting on the connecting rod are mainly caused by the interaction of piston and crank, the one is the force applied to the piston in the process of gas combustion and the other is the transverse load applied to the rod body caused by the complex movement in the whole movement of the connecting rod.

Figure 2 shows the motion structure diagram of crank and rod mechanism. In the figure, the $\mathrm{AB}$ is the connecting rod, $\mathrm{A}$ is the center of piston pin and small end of rod, B is the center of crank pin, the central line of the cylinder passes through the center of crank O, OB is the crank.

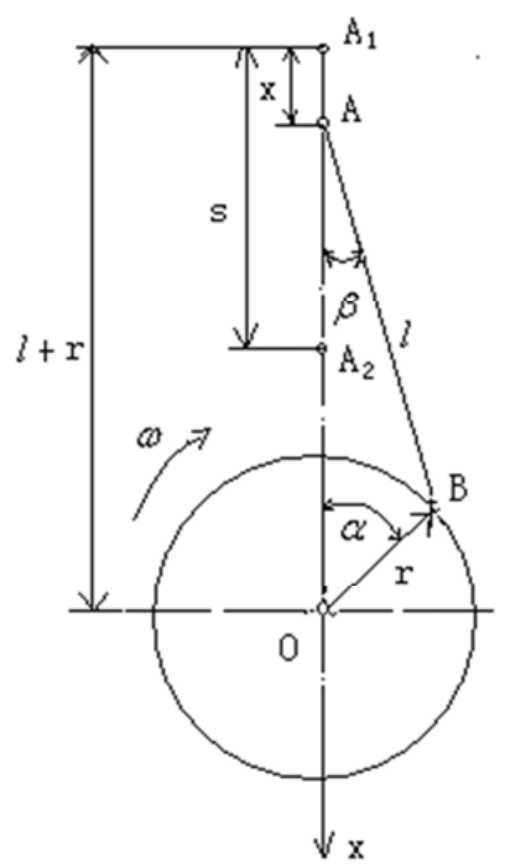

Figure 2. Motion structure diagram of crank and rod mechanism. 


\subsection{Boundary Conditions}

The boundaries are mainly divided into two conditions of pulled and compressed.

At the small end of the connecting rod:

$$
P_{j}=\int_{0}^{\beta} B_{1} q r_{1} \cos \beta d \beta=\int_{0}^{\beta} B_{1} q_{\max } r_{1} \cos \frac{3}{2} \beta \cos \beta d \beta=1.2 B_{1} r_{1} q_{\max }
$$

Where the $r_{1}$ is the radius of the small end of connecting $\operatorname{rod} ; \beta \in[0,2 \pi / 3], \mathrm{q}=\mathrm{q}_{\max } \cos \frac{3}{2} \beta$.

The pulled region of the small end of connecting rod is divided into 12 equal areas along the circumferential direction at intervals of $10^{\circ}$, assuming that the force in each area is uniform and equivalent to the assumed pressure applied by the cosine distribution. The equivalent pressure for each area is:

$$
P_{j n}=\left.\frac{B_{1} q_{\max } r_{1}}{2}[2 \sin (0.5 \times \beta)+0.4 \sin (2.5 \times \beta)]\right|_{\alpha} ^{\beta}
$$

The equivalent pulling force for each area is:

$$
\mathrm{q}_{\mathrm{dn}}=\mathrm{P}_{\mathrm{jn}} /\left.\left(\mathrm{B}_{1} \times \mathrm{r}_{1} \times \sin \beta\right)\right|_{\alpha} ^{\beta}
$$

At the big end of the connecting rod:

Assuming that the force satisfies the cosine distribution in the range of $180^{\circ}$ when it's pulled and compressed:

$$
\begin{gathered}
\mathrm{q}=\mathrm{q}_{\max } \cos \beta \\
\mathrm{P}_{\mathrm{j} 1}=\int_{0}^{\beta} \mathrm{B}_{2} \mathrm{qr} \mathrm{r}_{2} \cos \beta d \beta=\int_{\alpha}^{\beta} \mathrm{B}_{2} \mathrm{q}_{\max } \mathrm{r}_{2} \cos \beta d \beta=\frac{\pi}{2} \mathrm{~B}_{2} \mathrm{r}_{2} \mathrm{q}_{\max }
\end{gathered}
$$

When the big end of the connecting rod is compressed, the compression region is divided into 18 equal areas along the circumferential direction at intervals of $10^{\circ}$, assuming that the force in each area is uniform and equivalent to the assumed pressure applied by the cosine distribution. The equivalent pressure for each area is:

$$
\left.\mathrm{P}_{\mathrm{j} 2 \mathrm{n}} \frac{\mathrm{B}_{2} \mathrm{q}_{\max } \mathrm{r}_{2}}{2}[\beta+0.5 \sin (2 \times \beta)]\right|_{\alpha_{1}} ^{\beta_{1}}
$$

The equivalent pulling force for each area is:

$$
\mathrm{q}_{\mathrm{cn}}=\mathrm{P}_{\mathrm{j} 2 \mathrm{n}} /\left.\left(\mathrm{B}_{2} \times \mathrm{r}_{2} \times \sin \beta\right)\right|_{\alpha_{1}} ^{\beta_{1}}
$$

\section{Result Analysis}

\subsection{Analysis of Static Structure}

Without considering the influence of inertia and damping, the effect of structure under the fixed load was calculated and the load fluctuation of structure over time was analyzed. Simplifying the force of the moving connecting rod, the load that changes with time at the maximum gas pressure was calculated. The boundary condition is nonlinear. The fixed support was applied to the connecting surface of the big end and crank pin, and the surface load was applied on the inner surface of the small end at two conditions of pulled and compressed.

According to the calculation, the maximum gas pressure is 4.5 $\mathrm{MPa}$, the maximum axial force is $11016.32 \mathrm{~N}$. Applying
Assuming that the load $P_{j}$ at the small end of the connecting rod is in the range of $120^{\circ}$. It changes by the cosine law: the above mentioned loads to the upper surface of the small end of rod uniformly, the stress and strain distributions of the connecting rod at the static conditions of pulled and compressed were obtained, which were shown in Figure 3 and Figure 4.

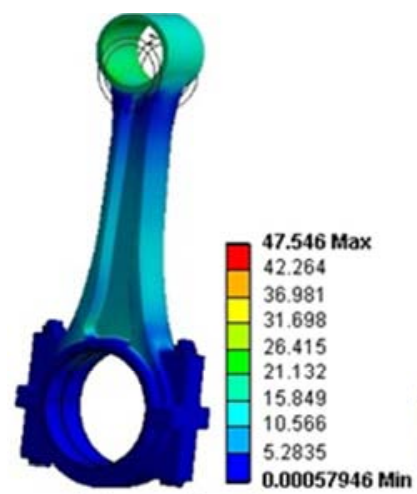

(a) Pulled

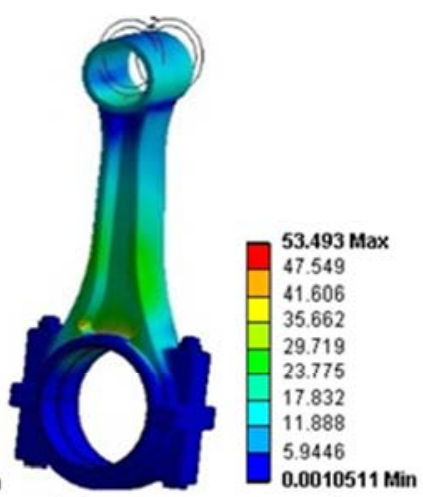

(b) Compressed
Figure 3. Stress distributions of the connecting rod at pulled and compressed (von-Mises).

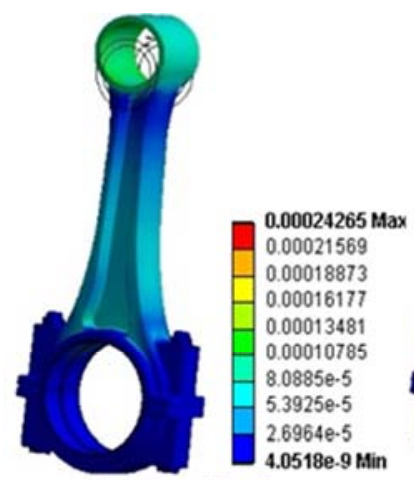

(a) Pulled

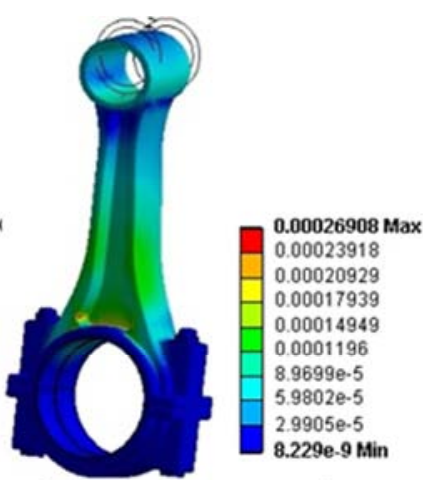

(b) Compressed
Figure 4. Strain distributions of the connecting rod at pulled and compressed (von-Mises).

As shown in Figure 3 and Figure 4, the stress is mainly concentrated in the small end of connecting rod, the stress on the inner surface of the small end of connecting rod is less than 36.981 $\mathrm{MPa}$, the stress on the outer surface is less than 31.298 $\mathrm{MPa}$, the maximum strain is less than $0.00024 \mathrm{~m}$, According to the checking calculation, the connecting rod is safe when it's pulled. The maximum stress and strain are at the transition region between big end and body, but the maximum deformation satisfies the safety factor of the connecting rod.

\subsection{Modal Analysis}

The operation of engine is a very complex and dynamic 
process that applying loads alternately. For this dynamic system, the relationships of loads frequencies and natural frequencies of the connecting rod must be taken into account: The one is resonance, when the perturbation frequencies of loads are close to the natural frequencies of system, the tiny load in structure can also cause the stress response and dynamic displacement response that are many times greater than static response and produce great destructive power. The other one is self-excited vibration, in dynamic systems, there will be suddenly vibrate without addition of alternating excitation under certain conditions, the suddenly increased amplitude can cause great damage and even damage the connecting rod. Modal analysis can be used to determine the vibration characteristics of structure and machine parts (natural frequencies and vibration modes) and find out the design defects to correct.

At the big end of the connecting rod, keeping the freedom of rotating around the center line and constraining the freedom of other directions. At the small end of rod, keeping the freedom of rotating around the piston pin and the freedom along the cylinder. Other degrees of freedom are given constraints. Figure 5 shows the analysis results of six modes.

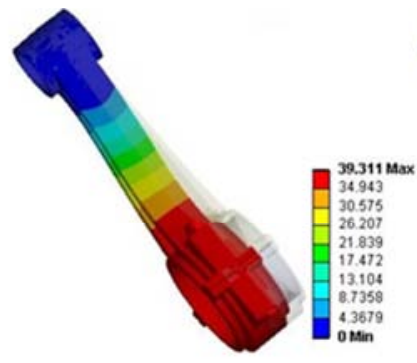

(a) Mode 1

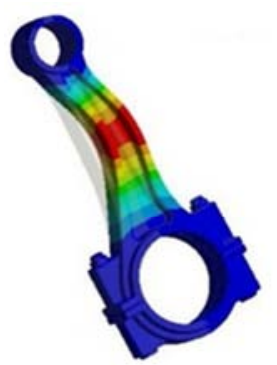

(c) Mode 3

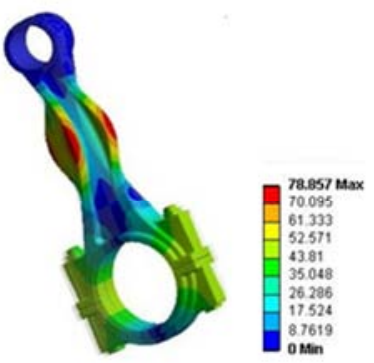

(e) Mode 5

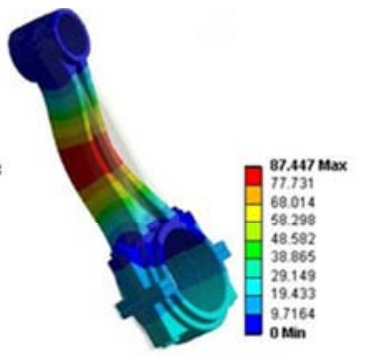

(b) Mode 2
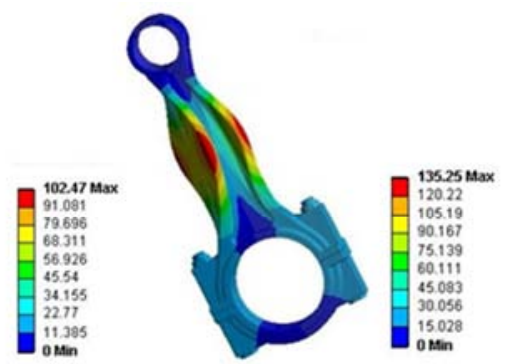

(d) Mode 4

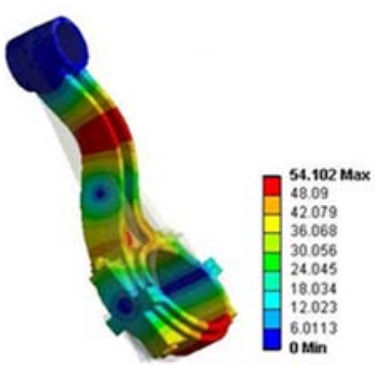

(f) Mode 6
Figure 5. Modal analysis of the connecting rod.

The modal analysis can be used to obtain the structural morphologies of vibration response and the positions of nodes in vibration under the certain vibration modes. The $Z$ axis is the direction along the length of connecting rod, the $\mathrm{Y}$ axis is determined by the right-hand rule, the $\mathrm{X}$ axis is the direction of center line of the big end. Table 3 shows the each frequency order of modal analysis.

Table 3. Each frequency order of modal analysis.

\begin{tabular}{ll}
\hline Modal & Frequency [Hz] \\
\hline Mode 1 & 856.81 \\
Mode 2 & 7256 \\
Mode 3 & 8963.5 \\
Mode 4 & 9094.5 \\
Mode 5 & 10535 \\
Mode 6 & 12081 \\
\hline
\end{tabular}

Although there are many frequency components in gas explosion pressure in the actual process of engine, many results of spectrum analysis for gas explosion pressure show that the spectrums of large energy are mainly in a relatively low frequency range which generally below $2000 \mathrm{~Hz}$. As shown in Figure 5 and Table 3, the frequency of the connecting rod is below $2000 \mathrm{~Hz}$ at Mode 1, the rod body flexural produces flexural vibrations around the $\mathrm{X}$ axis, the deformation of the transition region between big end and body is largest which is $54.102 \mathrm{~mm}$. The variations of each frequency order are relatively large. Beginning from the Mode 2 , the deformation of the connecting rod is relatively large, and the rod produces flexural vibrations around the $\mathrm{Y}$ axis which performs the flexure of rod body in the XOY plane; The Mode 3 produces flexural vibrations around the $\mathrm{Y}$ axis which is same as the Mode 2, but the difference is that the flexural degree of big end and rod body at Mode 2 is larger than Mode 3; The Mode 4 and Mode 5 produce flexural vibrations around the $\mathrm{Z}$ axis, the maximum deformation is produced at Mode 4 which is $135.25 \mathrm{~mm}$; The Mode 6 produces flexural vibrations around the $\mathrm{Y}$ axis and the maximum flexure is produced at Mode 6. In order to ensure that the dynamic stress of connecting rod in working process is not too large, the structure of rod should be adjusted and optimized appropriately to adjust the natural frequency properly to prevent resonance.

\subsection{Transient Dynamic Analysis}

To consider the inertia and damping force of the connecting rod, it's necessary to consider the change of load at different time. The transient dynamic analysis can be used to determine the change of displacement, force, stress and strain over time when the designed structure is in any combinations of static loads, harmonic loads and transient loads.

After keeping the freedom along the cylinder of the small end of connecting rod, constraining the freedom of other directions and applying torque to the big end of the connecting rod, the stress, axial velocity and radial displacement of the connecting rod at each moment were analyzed. Figure 6 shows the stress distribution of the connecting rod in transient dynamics analysis. 


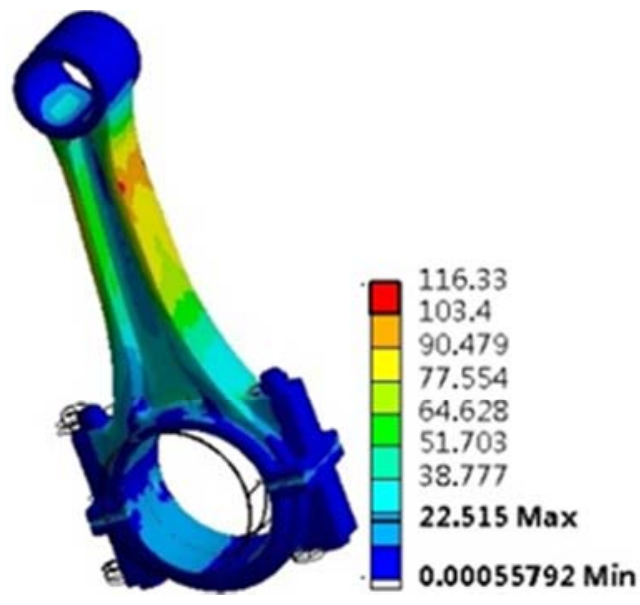

Figure 6. Stress distribution of the connecting rod.

As shown in Figure 6, the stress distribution at the body of connecting rod is larger. At the two ends of the connecting rod, the stress is about 30 50 MPa which is consistent with the static structure analysis. In the above figure of stress distribution, the Max and Min indicate the maximum and minimum stresses of the connecting rod in the last second, the maximum stress is $22.515 \mathrm{MPa}$, which is far less than the allowable stress. Figure 7 shows the curve of the maximum and minimum stress varies with time. The maximum and minimum stresses of the connecting rod first increase gradually with time, and then decrease gradually after the maximum values. The largest force of the connecting rod produces in the working stroke, the stress peak is at fifth second with the maximum value of $116.33 \mathrm{MPa}$. The stress is relatively large in the allowable range, in order to improve the safety factor to ensure the safety of the connecting rod, it's necessary to optimize the connecting rod.

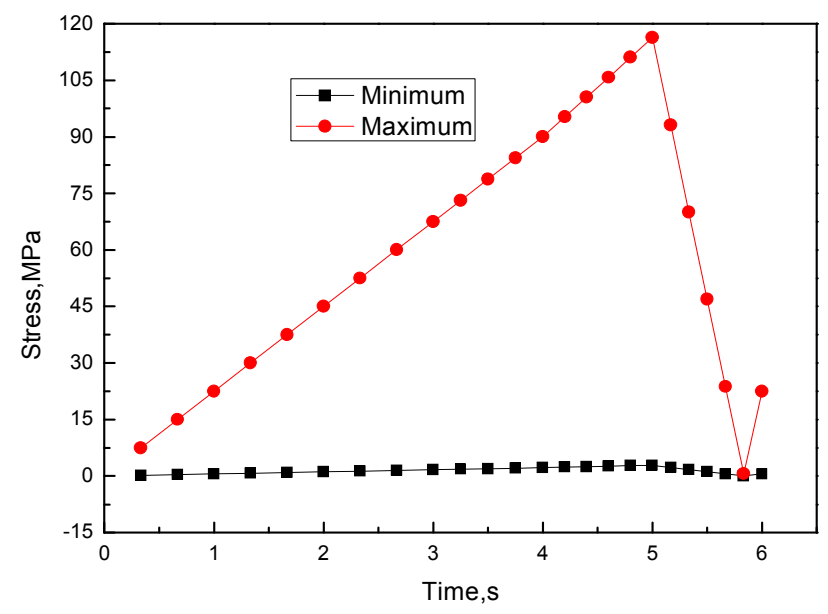

Figure 7. The curve of the maximum and minimum stress varies with time.

The Figure 8 shows the axial velocity distribution of the connecting rod and the maximum velocity is at the big end. The Figure 9 shows the maximum and minimum axial velocity values over time. As shown in Figure 9, the velocities of different parts of the connecting rod are different at each time, which conform to the actual working process of the connecting rod. The small end of rod makes reciprocate rectilinear motion along the cylinder, the big end of rod not only makes reciprocate rectilinear motion along the cylinder in the process of movement, but also makes high-speed rotary motion around the crankshaft and produces vibration. Therefore, the velocity of big end is greater than the small end.

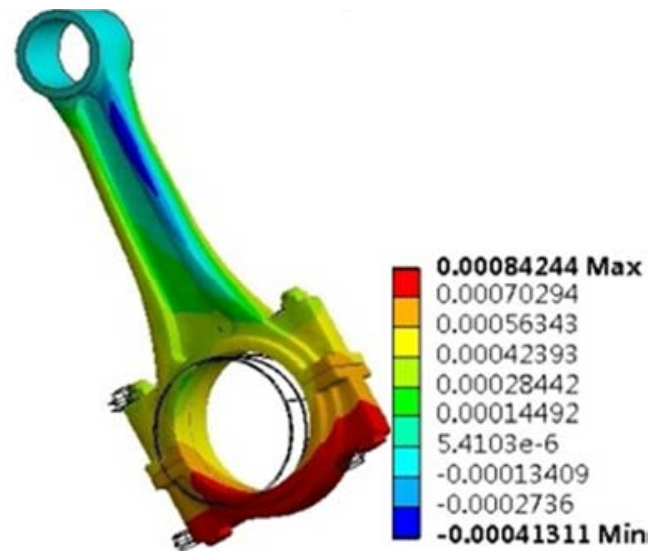

Figure 8. Axis velocity of the connecting rod.

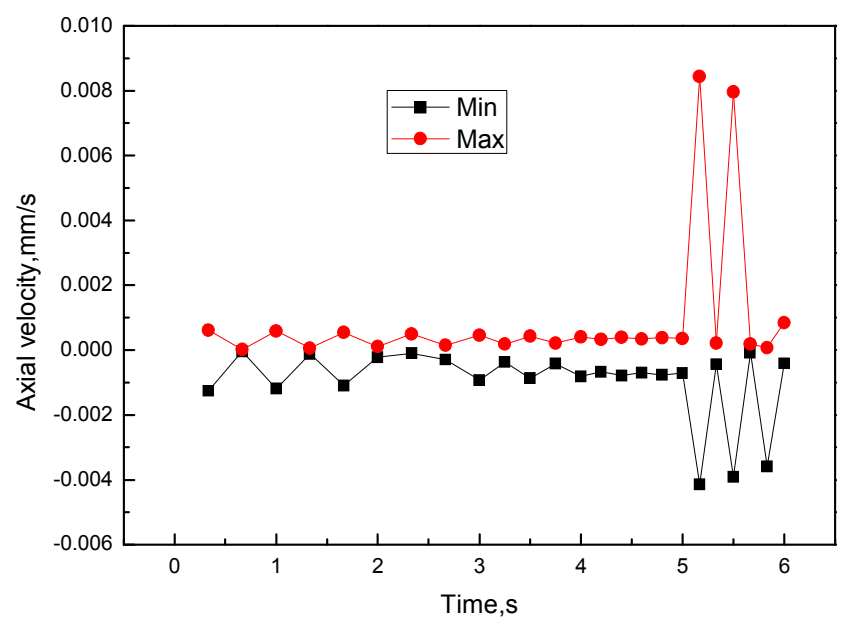

Figure 9. Maximum and minimum axial velocity values over time.

Figure 10 shows the radial displacement distribution of the connecting rod, Figure 11 shows the maximum and minimum radial displacements over time.

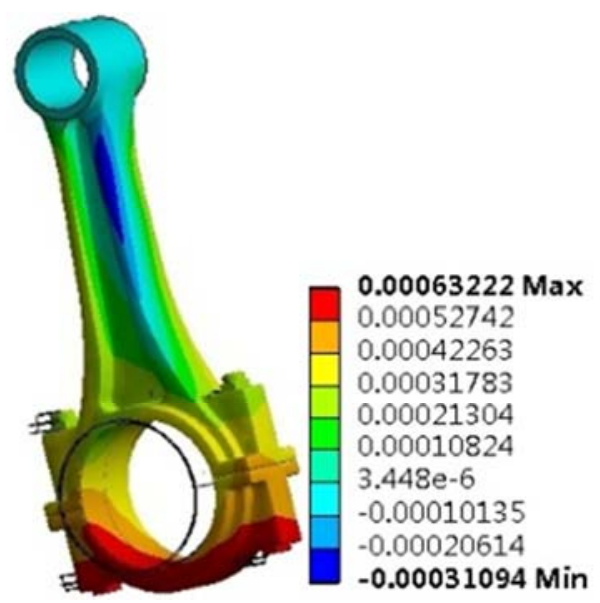

Figure 10. The radial displacement distribution of the connecting rod. 


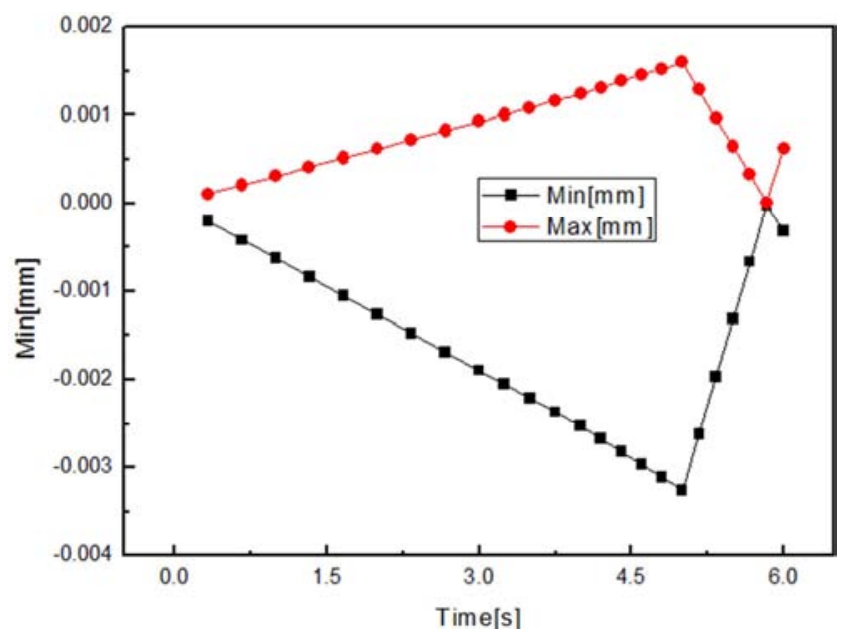

Figure 11. Maximum and minimum radial displacement over time.

According to the stress distribution of the connecting rod, the maximum stress produces at fifth second. As shown in Figure 11, the forward and backward maximum deformations occur at the fifth second too. And as shown in Figure 10, the displacement of the big end of rod is the largest. For general engines, the allowable value of deformation should be less than half of the gap in diametral direction while the standard gap is $0.012 \sim 0.031 \mathrm{~mm}$. As shown in Figure 11, the maximum radial deformation of the connecting rod is less than the allowable value.

\section{Conclusion}

In this research, The finite element method is used for linear static structure analysis of the connecting rod, the stress and strain of rod in conditions of pulled and compressed are analyzed by applying pressures and loads on rod. The results show that the stresses at the inner surface of the big end and the transition region between big end and rod body are the largest, but the maximum stress is less than the allowable value.

Considering the connecting rod in actual movement is subjected to alternating load, the modal analysis was applied on connecting rod, which reflects intuitively the frequencies of the rod in resonance. The analysis can prevent the connecting rod occurs resonance after reaching these frequencies and further causes serious consequences for engines. In addition, through the transient dynamic analysis of the connecting rod, the stress, displacement and velocity of rod at each moment are obtained.

\section{Acknowledgements}

The research work of this paper is supported by "Yanshan University postgraduate course construction project" (No. SF201607), thanks the project for its strong support.

\section{References}

[1] Yirong XIE, Tenggang XU, Jianjun ZHU. Optimization Design of Engine Connecting Rod Based on ANSYS Workbench [J]. Journal of Donghua University(Natural Science), 2015, 41 (4):527-531.

[2] Xiaoqing HU. Mechanical Properties Analysis of Motocar Engine Connecting Rod Based on ANSYS Workbench [J]. Manufacturing Automation, 2014 (4):107-109.

[3] Yulin WANG. FEA for Connecting Rod of Engine Based on AWE [J]. Machinery Design and Manufacture, 2013 (7):224-226.

[4] Kanwen XU, Jihua FAN, Dongxiang FAN, et al. Finite Element Analysis of Engine Connecting Rod Made of Different Materials [J]. Mechanical Engineering and Automation, 2017 (2):66-68.

[5] Zheng B, Ji L, Liu Y. Finite Element Analysis and Structural Improvement of Diesel Engine Connecting Rod [C]// Second International Conference on Computer Modeling and Simulation. IEEE Computer Society, 2010:175-178.

[6] Zhibo YANG, Pengfei LUO, Kaifei LIU. Optimal Design of Engine Connecting Rod Based on FEM [J]. Journal of Henan Polytechnic University(Natural Science), 2013, 32 (1):65-68.

[7] Sining PAN, Chuangang Huang, Shuanghua Yang, et al. Research on Lightweight Technology of Engine [J]. Automobile Technology and Material, 2013 (5):58-61.

[8] Peng LI. Foreign Research on Lightweight of Connecting Rod of Automobile Engine [J]. Automobile Technology and Material, 2012 (2):19-24.

[9] Tengteng LI, Shaohua ZHONG. Modal Analysis of Engine Connecting Rod Based on ANSYS [J]. Auto Engineer, 2010 (4):25-27.

[10] Rakic S, Bugaric U, Radisavljevic I, et al. Failure analysis of a special vehicle engine connecting rod $[\mathrm{J}]$. Engineering Failure Analysis, 2017, 79:98-109.

[11] Xuyang CHEN, The Static-Dynamic Strength Analysis and Structural Optimization of the Engine Connecting Rod [D]. Northeastern University.

[12] Peng LI, Baocheng ZHANG, Xing LI, et al. Finite Element Modal Analysis of Engine Connecting Rod Based on Hyperworks [J]. Journal of Tangshan College, 2011, 24 (3):31-33. 